\title{
AARP Newsmaker Interview with Dr. Mary Ann Tsao
}

A Conversation with the Chairman and Founding Director of the Tsao Foundation 


\title{
AARP Newsmaker Interview with Dr. Mary Ann Tsao
}

\author{
AARP recently sat down with Mary Ann Tsao, Chairman and Founding Director of the Tsao Foundation, a \\ Singapore-based non-profit foundation dedicated to aged care and aging issues. Dr. Tsao carries out the goals \\ and mission of her grandmother, Mrs. Tsao Ng Yu Shun, who founded the Tsao Foundation in 1993. The Tsao \\ Foundation aims to "disrupt aging" and seek "mindset and systemic change by implementing innovation in \\ community-based eldercare, training and education, policy relevant research, collaboration and advocacy."
}

\begin{abstract}
Why is the Tsao Foundation focusing on community-based approaches to care? What are the benefits of this approach?
\end{abstract}

MAT: One of the key missions of the foundation is to enable older people to age in place - to live in their own homes and the community - so in this regard, services need to be delivered where the seniors are.

Access is also a major issue. There are many barriers to care - whether it's the lack of information, difficulty navigating the health system or inaccessible transportation. Being part of the community allows us to have a deeper understanding of the issues and allow us to design more effective programs.

Another issue is that older people in Singapore frequently do not seek care, and may not accept care even when offered. Being part of the community and having social capital in the neighborhood helps reluctant elders accept services more easily.

Community based services can also more easily mobilize resources such as volunteer manpower.

In 2015 you opened the ComSa Whampoa center, a community-wide approach to integrated care that enables residents to age in place. What makes this center unique? What insights has the Tsao Foundation gleaned from this approach?

MAT: This center is unique because it provides a range of fully integrated health and social services that promote health, enable self-efficacy as well as meet a continuum of needs for older people from the well, to the frail and the dying. Core services include selfcare coaching, primary care, care management, center based care, care giver support as well as home and end of life care.
This is the first such center in Singapore and functions as a service hub, providing care in the community for older adults with complex needs, and acting as a bridge between the hospital and the community. A center piece is the Person Centered Medical Home (PCMH primary care plus care management), which provides geriatric care in the community.

The center also functions in the context of the ComSA health system (launched in 2013) within the community of Whampoa, which aims to catalyze a whole community approach to aging well and adopts a proactive, preventive, population health approach to health and longevity through several key components:

\section{A. Population health approach through community health survey - this is to identify population health issues (such as social isolation and dementia) so comprehensive and specific community-wide intervention strategies can be devised}

B. Identification of at risk individuals with bio-psycho-social health issues through a validated risk screener developed in associated with the population survey. Depending on their risk score and profile, individuals identified are referred to appropriate services; those who are previously without health consistent care are referred to ComSA PCMH

C. Health service system through the Whampoa community service network - this aims to rationalize how the currently fragmented service provision can be improved by creating a care delivery system

D. Community engagement and development programs - building platforms such as Rumah Whampoa and SCOPe (Self Care for Older People), which support the development of self-care capability, strengthen the collective voice of older people, promote greater participation and contribution to community life, as well as strengthen inter-generational relationships.

The key takeaways from the ComSA experience so far are:

1) the importance of having a systems approach to care delivery, especially for older people with complex needs. Otherwise, people fall through the crack or care is not optimally effective, as not all necessary services are delivered in a timely and organized manner and

2) the importance of taking a population approach to community service planning. Without the survey, we were blind to the extent of serious issues in the community, such as the $50+$ percent of older residents who are socially isolated with significant health risks.

Earlier this year you launched Rumah Whampoa, a traveling exhibition from the elders of Whampoa Centre, what were the reactions to the exhibition? What was a favorite exhibit of yours?

MAT: As mentioned earlier, Rumah Whampoa (which means my home, Whampoa) is a community platform for residents of Whampoa to connect with, and learn more about, their older members. The first two projects are Photovoice, where seniors created narratives based on their lives and times in Whampoa through photographs they took, and Intangible Stories, where seniors created stories around old objects that were precious to them and which they have held onto through their lives.

I loved the story about the old Singer sewing machine that seemed so useless, but 
had provided the family clothing made from fabric scraps and helped the family survive during tough times because of the extra sewing that grandma did, or the neatly curated stacks of old movie magazines whose stories of romance and glamour at a time of poverty and struggle gave hope and cause for a young lady to dream.

By bringing forth these stories and exhibiting them around different parts of the community, it benefited both the story "tellers" and the "listeners" as the former reveal and the latter learn about the rich legacy of the community held by the elders. This helps to connect the generations and generate healthy appreciation by the younger generations of the older ones, while also affirming the extraordinary lives of the older people for themselves.

All this helps as well to reset the mindset of older people in a positive way of how they think of themselves, as well as to combat ageist views among the young.

What current belief is the biggest impediment to an age-friendly society? How do you want to change that with your work?

MAT: The biggest impediment I believe is ageism: society's ignorance in assuming all older people are frail, dependent and need care, "non-productive," and that successive generation of older people will be the same. With the nuclear family an increasing Asian phenomenon as well, decreasing contact between grandparents and grandchildren and the lack of familiarity with older people also contribute to this continuing myth.

We have been effective to some degree in changing perception through providing evidence to specific policy makers, influencers and decision makers. Our Expert Series program brings critical thinkers and scholars to discuss and debate priority issues of interest to the government; experts range from World Bank economists, to government officials from other countries, as well as leading academics and practitioners from around the world. Commissioning local research and disseminating the data to relevant bodies, including the media, is also effective in getting issues onto the policy agenda as well as increasing the awareness of the broader public.
Programs that provide platforms for the voices of older people and which embolden them to advocate for themselves are also effective.

Nonetheless, much more need to be done. To combat ageism, there needs to be broad collaboration across stakeholders and a strategy for tackling ageism in different sectors, such as business. We hope to catalyze such an initiative moving forward.

Recently the Singapore government announced the Action Plan on Aging, 10 point action plan that aims to engage Singapore's aging population in volunteering, employment, and aging-in-place initiatives. What will the Tsao Foundation's role be in this initiative?

MAT: The Foundation championed aging in place since our inception in 1993 and has been creating and advocating for the mainstreaming of community care service models - where there had almost been none - to enable aging in place.

Likewise we have numerous initiatives for mature volunteers which approach as a learning and development program for our senior volunteers. The community development initiative in ComSA Whampoa also actively promotes senior volunteerism through various programs. Our Big Swing program aims to work with older residents not only to encourage volunteerism, but also support their leadership development to identify and act on community issues which they can actively address on their own.

Moving forward, we will be focusing on the notion of retirement and work - be it paid or unpaid, employment or enterprise - and stimulate discussion, research and innovation around this issue.

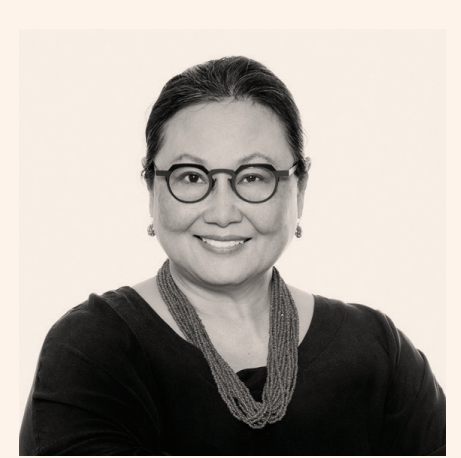

Mary Ann Tsao

CHAIRMAN AND

FOUNDING DIRECTOR OF

THE TSAO FOUNDATION 
AARP International engages global stakeholders to spark solutions that strengthen communities, protect the vulnerable and enable people around the world to pursue their goals and dreams. Working with governments, civil society and the private sector, we are focused on enhancing the quality of life for people as they age. We serve as the global voice for AARP, a social change organization with a membership of more than 37 million.

THE JOURNAL ONLINE

aarpinternational.org/journal

AARP INTERNATIONAL ONLINE

aarpinternational.org

FACEBOOK

facebook.com/aarpintl

TWITTER

@aarpintl

CONTACT

AARP International

601 E Street, NW

Washington, DC 20049

United States

T +1 2024342398

E international@aarp.org

AARP International: The Journal is a publication of AARP. The views expressed herein do not necessarily represent policies of AARP and should not be construed as endorsements. The mention of a product or service herein is solely for information to our readers and may not be used for any commercial purpose. AARP, which was established in 1958, is a nonprofit, nonpartisan organization with tens of millions of members ages 50 and older. State offices are located in all 50 states, the District of Columbia, Puerto Rico, and the Virgin Islands.

January 2018

()2018, AARP

Reprinting with permission only. 